\title{
Caracterización tributaria en barrios urbanos populares: caso Parroquia el Vecino
}

\section{Tax Characterization in Popular Urban Districts: case Parish El Vecino}

\author{
Andrea Piedra Méndez* \\ mbastidas@ups.edu.ec \\ Juanita Salinas Vásquez \\ rbenites@ups.edu.ec \\ Juan Vázquez Loaiza \\ jvazquez@ups.edu.ec
}

\begin{abstract}
Resumen
La investigación que se realizó fue de tipo descriptiva y su objeto de estudio consistió en caracterizar tributariamente la actividad productiva desarrollada en la parroquia urbana El Vecino del cantón Cuenca, que es un espacio popular, diverso y dinámico con marcadas vulnerabilidades y fuertes contrastes. Se logró determinar la heterogeneidad de la actividad empresarial, su naturaleza constitutiva, entre otros aspectos. La información económica y financiera obtenida resultó interesante al momento de analizar la relación entre ingresos, costos y gastos, además de que identificó los criterios empresariales en el manejo del efectivo de los emprendimientos, por último se detectó la percepción sobre la calidad en la atención por parte del Servicio de Rentas Internas a los usuarios, incidencia cultural y nivel de cumplimiento de deberes y obligaciones tributarias.
\end{abstract}

\section{Palabras clave}

Tributación, caracterización socioeconómica, caracterización tributaria.

\footnotetext{
* Ecuatoriana. Máster en Contabilidad y Finanzas con mención en Gerencia y Planeamiento Tributario. Universidad Politécnica Salesiana- Cuenca. Docente.

** Ecuatoriana. Máster en Gestión de Empresas. Universidad Politécnica Salesiana- Cuenca. Docente.

*** Ecuatoriano. Máster en Ciencias de la Computación. Universidad Politécnica Salesiana- Cuenca. Docente.
} 


\begin{abstract}
The research was descriptive in nature and its object of study was to fiscally characterize the productive activity in the urban parish El Vecino from canton Cuenca, which is a popular, diverse and dynamic space with marked vulnerabilities and strong contrasts. It was possible to determine the heterogeneity of the business activity, its constitutive nature, among others. The economic and financial information obtained was interesting at the moment that the relationship between revenues, costs and expenses was analyzed. It also allowed the identification of the business criteria in cash management of entrepreneurships. Finally the perception of the quality in customer service by the Internal Revenue Service by users was detected, and also its cultural impact and level of fulfillment of duties and tax obligations.
\end{abstract}

\title{
Keywords
}

Taxation, socioeconomic characterization, tax characterization.

Forma sugerida de citar: Piedra Méndez, Andrea Fabiola, Salinas Vásquez, Juanita Virginia, \& Vázquez Loaiza, Juan Pablo (2016). Caracterización tributaria en barrios urbanos populares: Caso Parroquia El Vecino. Revista Retos, 11(1), pp. 88-104.

\section{Introducción}

El artículo sintetiza la investigación realizada respecto a la caracterización tributaria ${ }^{1}$ de la actividad productiva desarrollada en la Parroquia "El Vecino" del cantón Cuenca, identificando el perfil productivo y tributario del contribuyente, dando respuestas a las siguientes interrogantes: ¿Cuál es la tipología del contribuyente?, ¿cuál es la naturaleza de las actividades productivas?, ¿cuáles son las particularidades socioeconómicas

1 Determinar las particularidades socioeconómicas de las actividades productivas que inciden en su naturaleza tributaria, tales como magnitud de la actividad, nivel de formación del personal, incorporación al sistema financiero, cultura tributaria, entre otros aspectos. del contribuyente?; y, ¿cuál es el nivel de cultura tributaria existente?

Esta investigación responde a la necesidad de mejorar la caracterización tributaria, fortaleciendo la vigencia del mandato constitucional que proclama el carácter social y solidario del sistema económico ecuatoriano, que reconoce al ser humano como sujeto y fin de su accionar y establece una nueva orientación en el quehacer y convivencia del Estado con la sociedad (Const., 2008, Art. 283).

Este esquema constitucional, propicia el diseño y aplicación de una política económica de carácter inclusiva, que asegure una adecuada distribución del ingreso y la riqueza, adquiriendo así el régimen tributario interno, una 
especial responsabilidad en este sentido (Const., 2008, Art. 285).

En Ecuador, el potencial redistributivo de los tributos está condicionado a elementos complejos de la historia económica y social, que significan por una parte la necesidad de fortalecer la cultura tributaria desde el enfoque de ciudadanía fiscal y por otra parte intensificar la tributación directa en relación con la indirecta, reducir los niveles de evasión y elusión fiscal; y, definir coherentemente el destino y orientación del gasto público, con activa participación ciudadana en la gestión y fiscalización de recursos (Carrasco Vicuña et al., 2012). La política tributaria redistributiva, se sustenta en el reconocimiento ético de la justicia como un esfuerzo por garantizar las libertades reales y efectivas de las personas a partir de la igualdad de capacidades y oportunidades para lograr estados del ser y del bienestar (Sen, 1999).

El fortalecimiento de la ciudadanía fiscal, es decir, conocer y asumir voluntariamente las obligaciones tributarias y los derechos fiscales de consulta, reclamo, revisión de sentencias, entre otros, constituye un importante aspecto que busca potenciar la naturaleza redistributiva de la tributación, permitiendo mantener la cohesión social en realidades tan dispersas como la ecuatoriana (Hopenhayn, 2008).

La ciudadanía fiscal constituye así un reto para el fortalecimiento de la cultura tributaria, puesto que representa la conciencia de las personas, grupos e instituciones, acerca de sus responsabilidades y compromisos con la construcción de una sociedad cohesionada, democrática y justa. En este sentido el Servicio de Rentas Internas, ha realizado un importante esfuerzo por promover la cultura tributaria y el ejercicio de deberes y derechos tributarios (SRI, 2014).

La responsabilidad redistributiva del Estado es compartida con la ciudadanía, bajo el denominado "Pacto fiscal, por la justicia, la equidad y la libertad", que contempla interacciones sociales y objetivos comunes bajo una nueva estructura y nivel impositivo; y, una coherente asignación del gasto (Carrasco Vicuña et al., 2012).

Con esta investigación se pretende fortalecer la construcción de ciudadanía fiscal en los sectores urbano-populares de la ciudad de Cuenca, reconociendo sus especificidades productivas y tributarias, a partir de un caso específico de estudio, la parroquia urbana "El Vecino", localizada en la parte norte del centro histórico de la ciudad de Cuenca, con una superficie de $3.6 \mathrm{~km}^{2}$, que presenta una intensa y diversa actividad económica, que conjuga micro emprendimientos de carácter personal y familiar, con pequeñas, medianas y grandes empresas de capital. La parroquia "El Vecino", cuenta con una población de 30737 habitantes, 
que representan el 9\% respecto al total poblacional del Cantón Cuenca, ocupa el tercer lugar en densidad poblacional (8 $562 \mathrm{hab} / \mathrm{km}^{2}$ ), luego de las parroquias Yanuncay y San Sebastián respectivamente (INEC, 2010).

La investigación reconoce que el éxito de un pacto fiscal se mide por el grado en que se incorpore a los diversos grupos sociales en las discusiones, el cumplimiento y la vigilancia de ciertos acuerdos sobre la forma como se financia el Estado y se utilizan los recursos públicos (Lora, 2008). Considerando que los tributos constituyen un aporte solidario, que realizan los contribuyentes como actores del desarrollo colectivo, reflejando su compromiso personal en la construcción colectiva del Estado, el reconocimiento certero de la estructura productiva, económica y social de cada localidad, resulta indispensable para incidir positivamente en un proceso de desarrollo justo y equitativo" (Orduna Díez, 2003, pp. 173 - 174). "Los tributos, además de ser medios para recaudar ingresos públicos, servirán como instrumentos de política económica general, ... atenderán a las exigencias de estabilidad y progresos sociales y procurarán una mejor distribución de la renta nacional" (Código Tributario, 2014).

La microempresa en el Ecuador, acoge a un importante segmento del mercado laboral, con emprendimientos que operan en gran medida dentro de la informalidad, aproximada- mente el 33,50\% de los hogares del área urbana se sostienen con este tipo de actividad, resultando que apenas un cuarto de las mismas tienen Registro Único del Contribuyente (RUC) y licencia municipal; menos del 15\% están inscritas en el Sistema de Seguridad Social; y, solamente el 20\% llevan registros financieros formales (USAID, 2005).

La investigación contribuye con una aproximación al potencial tributario de la parroquia "El Vecino", espacio representativo del sector urbano popular del Cantón Cuenca, que registra para el 2014 según información proporcionada por el Servicio de Rentas Internas SRI, 4875 contribuyentes, el $7 \%$ con respecto al cantón. En la zona urbana de la ciudad de Cuenca existen 20585 establecimientos empresariales, que representan la mayor densidad a nivel nacional con 538 emprendimientos por cada 10000 habitantes (Tobar, 2013). La actividad productiva se concentra, a nivel micro empresarial en el sector de comercio seguida por servicios y manufactura respectivamente (INEC, 2010).

La microempresa en Cuenca, absorbe el 59\% de la ocupación laboral y representa el 94,9\% del total de unidades productivas existentes en el cantón (Tobar, 2013, p. 122), se ha incorporado significativamente al Régimen Impositivo Simplificado Ecuatoriano, vigente desde el 2008, 
logrando con ello reducir su grado de informalidad y contribuir a mejorar los niveles de recaudación tributaria en la ciudad de Cuenca (Montesdeoca \& Espinoza, 2015).

A partir del 2008, con la vigencia de la Ley Reformatoria para la Equidad Tributaria en el Ecuador, se dio gran importancia a la carga tributaria sobre la imposición directa; principalmente a las grandes riquezas de personas físicas con residencia en el Ecuador, que detectan grandes fortunas y acumulan caudales patrimoniales por medio de estructuras jurídicas y económicas muy bien construidas (Asencio, 2014, p. 53).

El estudio realizado por (Tobar, 2015) "Análisis Competitivo de las Pequeñas y Medianas Empresas en Cuenca Ecuador", señala que en el ámbito financiero el 90\% conoce la rentabilidad de los productos y servicios que ofrece, el desempeño de las empresas se ve afectado por temas políticos del país. En el aspecto económico uno de los principales temas expuestos es el tributario. Se muestra una importante afiliación a gremios productivos, ya que el $98 \%$ se encuentra afiliado a diversas organizaciones empresariales, de las que han recibido principales apoyos en temas de capacitación.

\section{Metodología}

El estudio de campo se realizó a novecientos diecinueve actividades que representan el universo productivo de la parroquia "El Vecino", aplicando una encuesta estructurada en cinco secciones: información general, caracterización socio-económica, cumplimiento de deberes formales y obligaciones tributarias, cultura y motivaciones tributarias, y percepción de la calidad de los servicios ofrecidos por el Servicio de Rentas Internas.

El formulario de la encuesta contiene cincuenta y siete preguntas con opciones cerradas, múltiples y abiertas; que fueron sistematizadas con promedios y rangos.

La aplicación de la encuesta se realizó según la zonificación territorial del Instituto Nacional de Estadísticas y Censo (INEC) para la $\mathrm{Pa}$ rroquia El Vecino, a pesar de que no todas las empresas brindaron acceso a la información, si fueron consideradas para tener un registro total de la actividad económica de la parroquia.

\section{Resultados}

\section{Identificación tributaria}

En la parroquia El Vecino, la actividad productiva predominante por clase de contribuyente se ubica bajo el Régimen Impositivo Simplificado Ecuatoriano "RISE". El segundo grupo en importancia tributaria, corresponde a "Otros contribuyentes", integrado por personas naturales, sociedades no calificadas como contribuyentes especiales y los no inscritos 
en el RISE. En el gráfico 1 apenas el 5.4\% de las actividades se ubican en el grupo de "Contribuyentes Especiales", mientras que el $9.5 \%$ no se identifica plenamente con ninguna categoría es- tablecida por el Régimen Tributario. Es importante destacar que el $12.9 \%$ de empresas niega la información, el $21 \%$ se ubican en el rubro de otros y el $51 \%$ se acogen al RISE.

\section{Gráfico 1. Clase de contribuyente}

\begin{tabular}{|r|c|}
\hline \multirow{2}{*}{ RISE } & \multicolumn{2}{|c|}{$21 \%$} \\
\cline { 2 - 2 } Otros (personas naturales, $\ldots$ ) & $12,9 \%$ \\
Niega información & $9,5 \%$ \\
Ninguno de los anteriores & 21\% \\
Contribuyente especial & $5,4 \%$ \\
\hline
\end{tabular}

Fuente: Elaboración propia, Encuesta Caracterización Tributaria de la Actividad Empresarial en la Parroquia El Vecino del Cantón Cuenca, 2013.

Gráfico 2 de acuerdo a la Clasificación Nacional de Actividades Económicas CIIU Revisión 4.0 la actividad predominante en la parroquia corresponde a Comercio al por mayor y menor y reparación de vehículos automotores alcanzando el 54,6\%, seguido por Otras Actividades de Servicios con el 28,2\%, Actividades de alojamiento y servicios de comida con el $4,8 \%$ y en menor medida actividades desarrolladas con Industrias Manufactureras y Artes, entrenamiento y recreación.

\section{Gráfico 2. Las actividades más frecuentes}

YG) Comercio al por mayor y al por menor;

S) Otras actividades de servicio

3I) Actividades de alojamiento y servicios de comida

C) Industrias Manufactureras

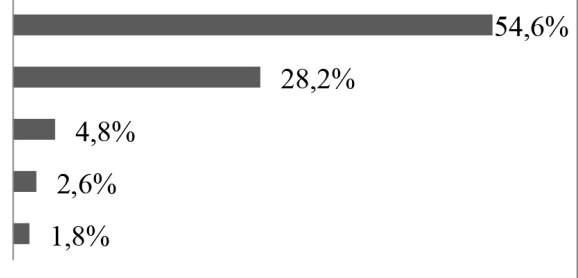

$\& R)$ Artes, entretenimiento y recreación

Fuente: Elaboración propia, Encuesta Caracterización Tributaria de la Actividad Empresarial en la Parroquia El Vecino del Cantón Cuenca, 2013. 
Caracterización socioeconómica de la actividad empresarial en la parroquia

La parroquia cobija de manera dinámica empresas de reciente creación, con actividades consolidadas, el
$8 \%$ no alcanza a cumplir un año de creación, mientras que el $37,7 \%$ tienen una antigüedad que no supera los cinco años. Gráfico 3.

\section{Gráfico 3. Años de vida del emprendimiento}

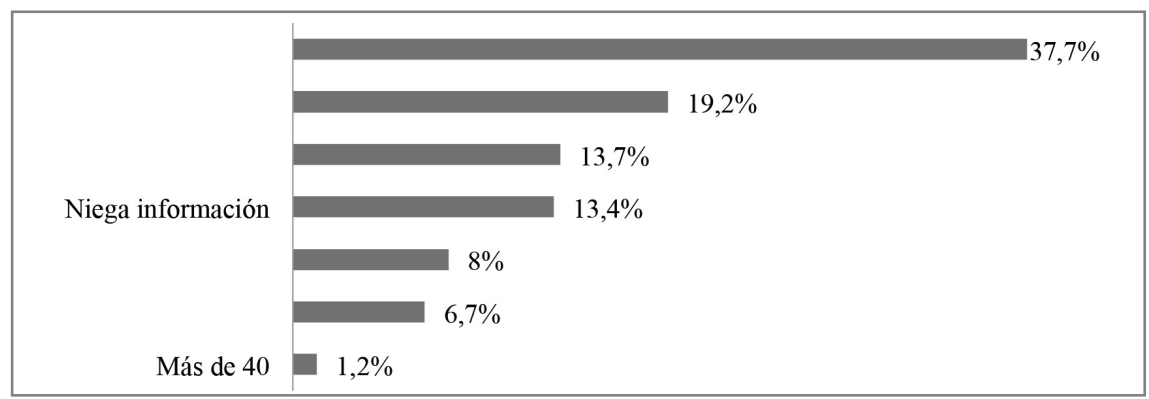

Fuente: Elaboración propia, Encuesta Caracterización Tributaria de la Actividad Empresarial en la Parroquia El Vecino del Cantón Cuenca, 2013.

Respecto al nivel de capacitación del personal de dirección y operación, se identificó que el 47,63\% de las/os trabajadores, tienen formación secundaria y apenas el 3,62\% alcanza nivel de posgrado. Gráfico 4.
Las empresas de la parroquia, son mayoritariamente administradas por su propietario con un nivel de instrucción que no supera la educación básica, y sin embargo cumplen funciones de contaduría.

\section{Gráfico 4. Nivel de instrucción formal del personal}

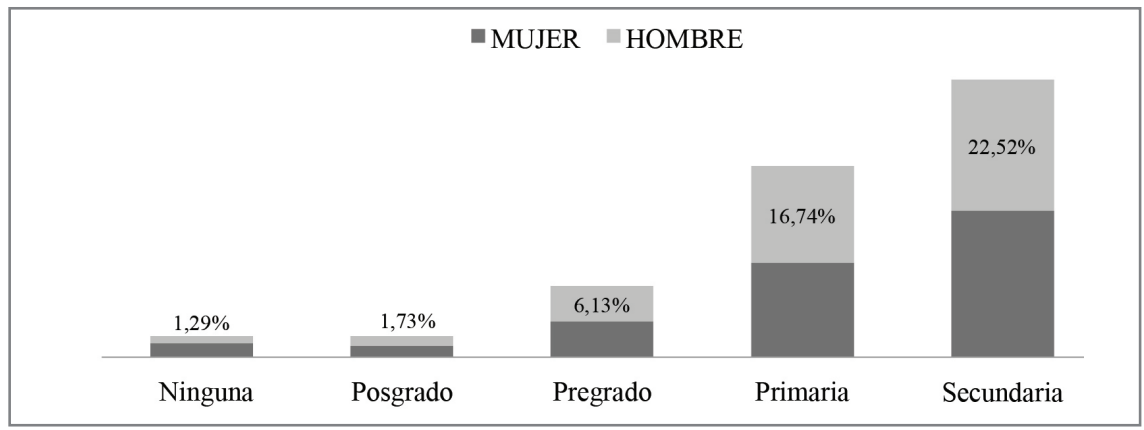

Fuente: Elaboración propia, Encuesta Caracterización Tributaria de la Actividad Empresarial en la Parroquia El Vecino del Cantón Cuenca, 2013. 
Financieramente, las actividades económicas en su mayoría tienen un movimiento promedio mensual de compra a proveedores de aproxima- damente $\$ 1000$ y de venta a clientes de $\$ 500$. Entre los gastos destacan los servicios básicos, arriendos y sueldos. Gráfico 5.

\section{Gráfico 5. Comparación de compras versus ventas}

\begin{tabular}{|c|c|c|}
\hline & a. Compras & b. Ventas \\
\hline $\begin{array}{r}\text { De } \$ 1 \text { a } \$ 1.000 \\
\text { Niega información } \\
\text { De } \$ 1.001 \text { a } \$ 5.000 \\
\text { De } \$ 5.001 \text { a } \$ 10.000 \\
\text { De } \$ 10.001 \text { a } \$ 50.000 \\
\text { De } \$ 50.001 \text { a } \$ 100.000 \\
\text { Más de } \$ 100.000\end{array}$ & \begin{tabular}{|l|} 
\\
$=1,9 \% 2$ \\
$1,3 \%$ \\
$0,5 \%$ \\
$0,2 \%$
\end{tabular} & \begin{tabular}{r|cr} 
Entre $\$ 10$ y $\$ 500$ & & $32 \%$ \\
Niega información & & $17,5 \%$ \\
Entre $\$ 1,001$ y $\$ 5.000$ & & $1,1 \%$ \\
Entre $\$ 501$ y $\$ 1.000$ & & $14,5 \%$ \\
Entre $\$ 5.001$ y $\$ 20.000$ & $3,4 \%$ & \\
Entre \$20.001 y $\$ 50.000$ & $1 \% \%$ \\
Más de $\$ 50.000$ & $0,5 \%$ &
\end{tabular} \\
\hline
\end{tabular}

Fuente: Elaboración propia, Encuesta Caracterización Tributaria de la Actividad Empresarial en la Parroquia El Vecino del Cantón Cuenca, 2013.

Es importante señalar que mayormente se intercambian bienes y servicios gravados con IVA tarifa $12 \%$ (67\% en compras y $39 \%$ en ventas), contrastando con el 10,8\% de emprendimientos que realizan adquisiciones sin comprobante de venta. Gráfico 6.

Gráfico 6. Compras y ventas por tarifa de IVA

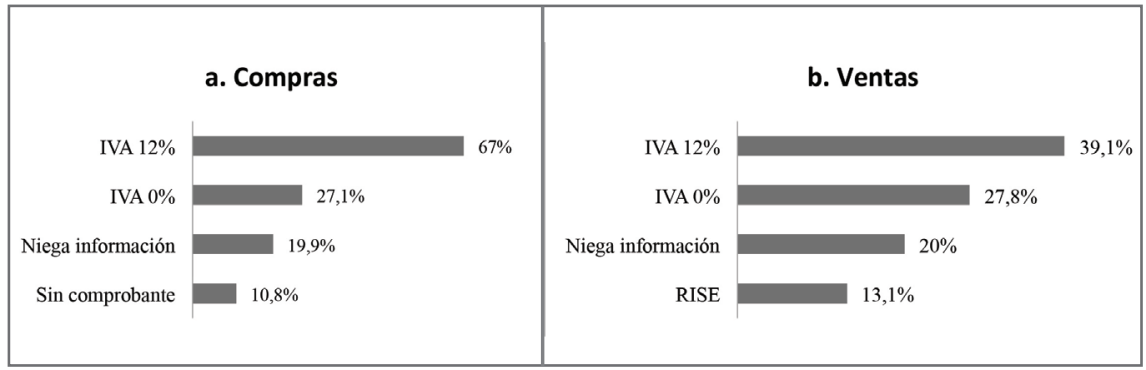

Fuente: Elaboración propia, Encuesta Caracterización Tributaria de la Actividad Empresarial en la Parroquia El Vecino del Cantón Cuenca, 2013.

Las transacciones de compra y en efectivo, el crédito bordea el $25 \%$. venta, se realizan mayoritariamente Gráfico 7. 


\section{Gráfico 7. Tipo de cobranza y forma de pago}

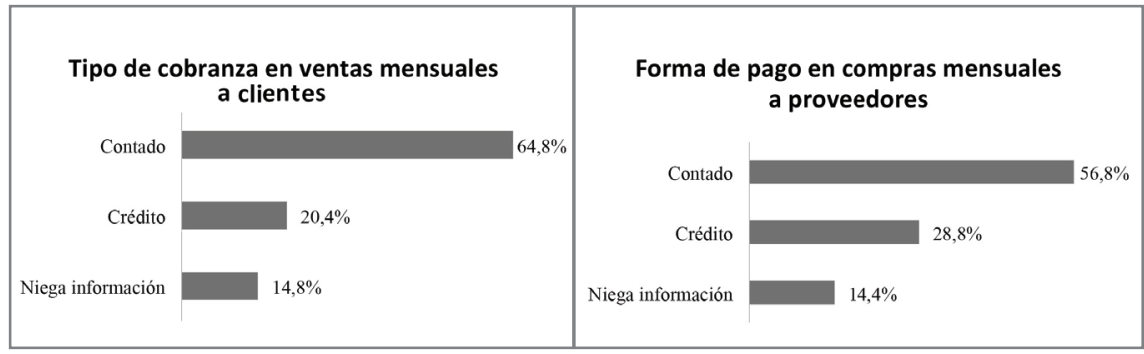

Fuente: Elaboración propia, Encuesta Caracterización Tributaria de la Actividad Empresarial en la Parroquia El Vecino del Cantón Cuenca, 2013.

Solamente el $20 \%$ de las empresas llevan el registro de su actividad económica a través de un sistema de información contable, contrastando con un $30 \%$ que no realiza ningún tipo de registro. El 21,9\% llevan un mínimo control de su actividad económica pues cumplen con el llenado y mantenimiento actualizado del registro de ingresos y gastos que representa una obligación tributaria.

Los resultados indican que el $55,9 \%$ de los emprendimientos no usan internet, mientras el 40,1\% no mantienen cuentas en el sistema financiero nacional. Gráfico 8.

Gráfico 8. Manejo de cuentas

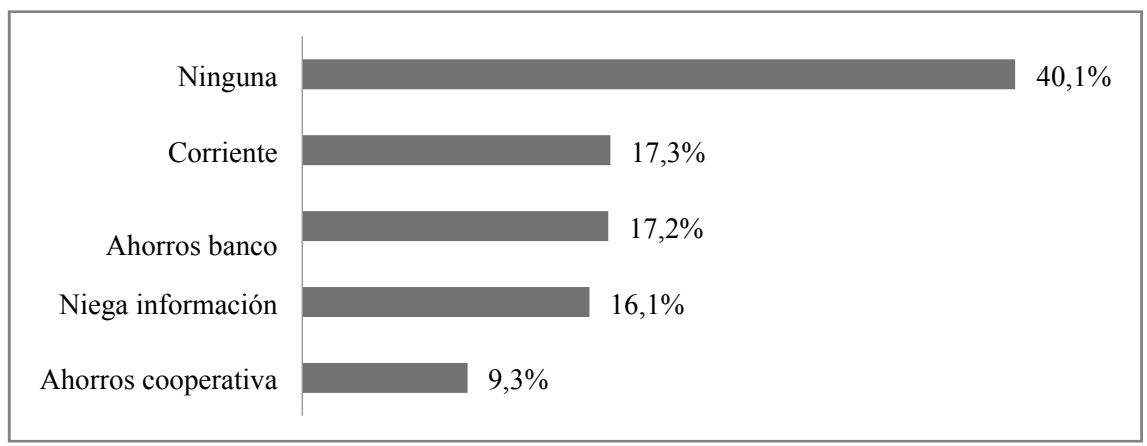

Fuente: Elaboración propia, Encuesta Caracterización Tributaria de la Actividad Empresarial en la Parroquia El Vecino del Cantón Cuenca, 2013 
Nivel de cumplimiento de deberes formales y obligaciones tributarias

El 70\% de las empresas no ha sufrido retrasos en el pago de sus obligaciones tributarias. El 28,1\% han sido inspeccionadas por funcionarios del SRI y apenas el 4,3\% han sido sancionadas (multa 2,5\%, clausuradas $1,6 \%$ y suspendidas en sus actividades 0,2\%). Gráfico 9.

\section{Gráfico 9. Retrasos en el pago de obligaciones tributarias}

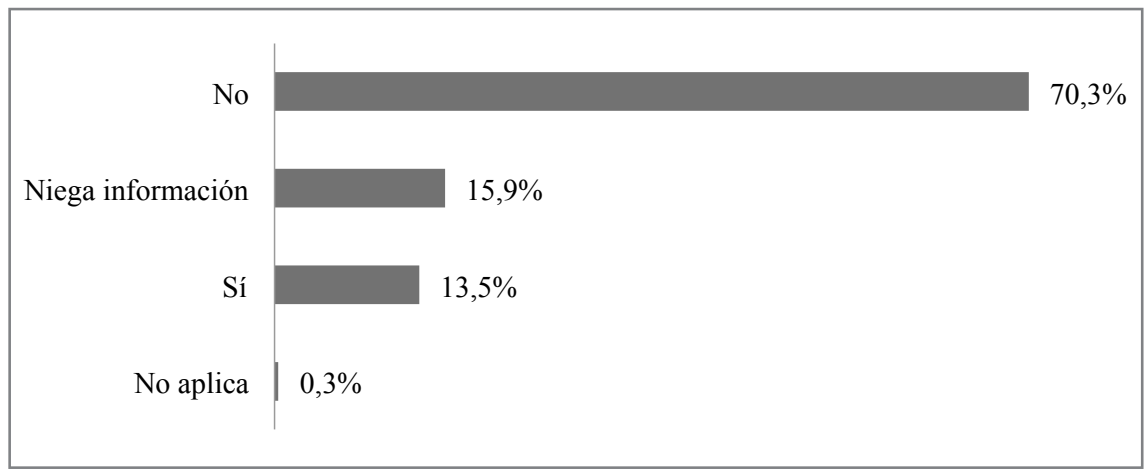

Fuente: Elaboración propia, Encuesta Caracterización Tributaria de la Actividad Empresarial en la Parroquia El Vecino del Cantón Cuenca, 2013.

Cultura y motivaciones tributarias

En la parroquia el $16,4 \%$ de quienes dirigen actividades económi- cas empresariales han participado en procesos de capacitación tributaria auspiciados por el SRI. Gráfico 10.

\section{Gráfico 10. Participación en cursos de capacitación tributaria}

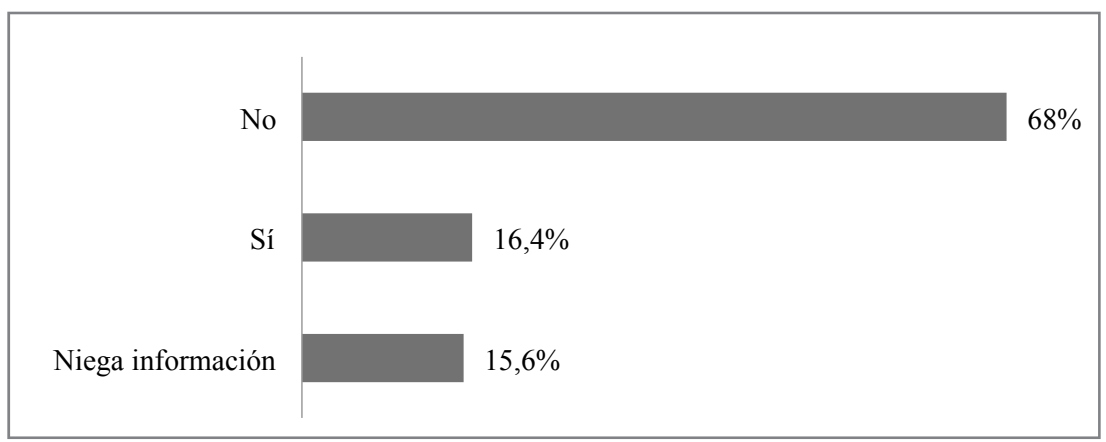

Fuente: Elaboración propia, Encuesta Caracterización Tributaria de la Actividad Empresarial en la Parroquia El Vecino del Cantón Cuenca, 2013. 
El 47,7\% de los contribuyentes cumplen sus obligaciones tributarias por temor a sufrir sanciones, apenas el $34.4 \%$ percibe el cumplimiento de sus deberes tributarios como una responsabilidad ciudadana y una contribución al desarrollo del país. Gráfico 11.

\section{Gráfico 11. Motivación en el cumplimiento}

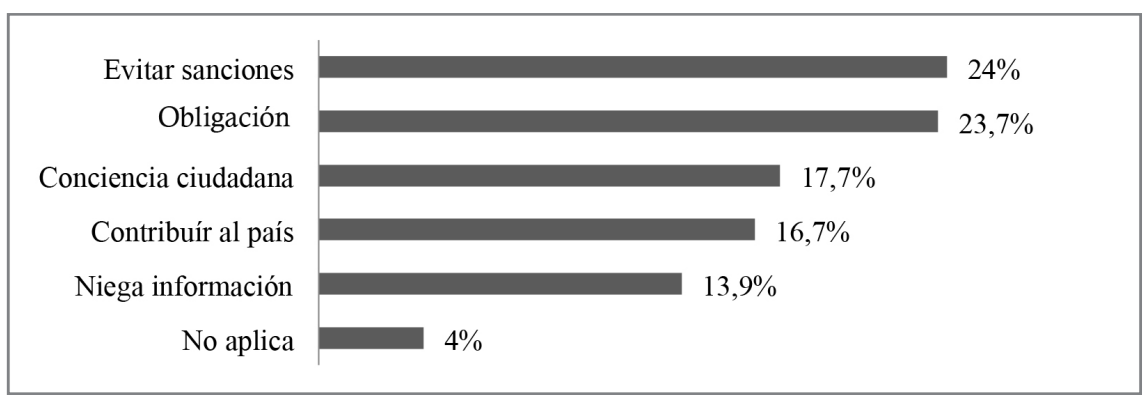

Fuente: Elaboración propia, Encuesta Caracterización Tributaria de la Actividad Empresarial en la Parroquia El Vecino del Cantón Cuenca, 2013.

Percepción de la calidad de los servicios ofrecidos por el Servicio de Rentas Internas

Un $70 \%$ de los contribuyentes encuestados consideran que la atención recibida del SRI está entre "muy buena" y "buena". El 3\% de las empresas encuestadas ha experimentado malos tratos en la atención por parte de los funcionarios de la entidad pública; en tanto que el 0,7\% ha percibido actuaciones indebidas. Gráfico 12.

\section{Gráfico 12. Trato del personal del SRI}

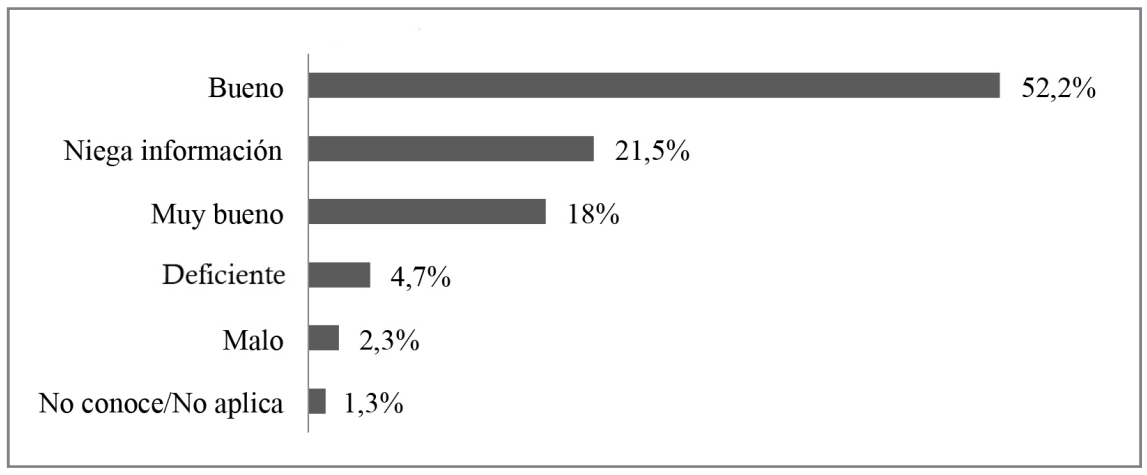

Fuente: Elaboración propia, Encuesta Caracterización Tributaria de la Actividad Empresarial en la Parroquia El Vecino del Cantón Cuenca, 2013. 


\section{Discusión}

La investigación aporta a la caracterización económica y social del cantón Cuenca, específicamente relacionada con la actividad productiva y tributaria de la parroquia El Vecino. Un valioso aporte para el tema de investigación es el realizado por (Tobar, 2014) quien elabora un detallado diagnóstico de las pequeñas y medianas empresas en Cuenca dando a conocer su impacto en la economía de la localidad.

Con la caracterización tributaria en barrios urbanos populares, caso parroquia El Vecino, se identifica que un gran número de las actividades económicas se encuentran bajo el sistema RISE, situación confirmada por el estudio sobre el impacto económico al mismo régimen realizado por (Quituisaca \& Sinchi, 2012), que demuestra la acogida del nuevo sistema por parte de las pequeñas unidades económicas familiares, clasificadas como de subsistencia y micro empresarial.

Aquellos contribuyentes que se negaron a dar información, pasarían a engrosar el sector informal de la parroquia, que sin tributar se beneficiarían de los servicios que presta el Estado, debilitando el pacto social y la ciudadanía fiscal.

Los resultados permiten identificar la fuerte presencia de actividades económicas débiles y vulnerables, carentes de adecuadas herramientas de la gestión empresarial administrativa

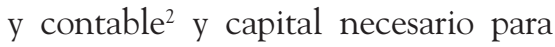
vislumbrar un horizonte de crecimiento sostenido, presentando un corto ciclo de vida empresarial, financiera y económica, los resultados operacionales son insuficientes para garantizar la permanencia de la actividad productiva en el mercado.

Un factor de significativa importancia en el sistema tributario está relacionado con el tema laboral, los resultados del estudio demuestran que la población femenina tiene mayor participación bajo los diferentes tipos de relación laboral y presenta un avance significativo en su nivel de instrucción.

Los micro y pequeños emprendimientos $^{3}$ de la parroquia, presenta un bajo uso del internet y de medios virtuales en su gestión empresarial, siendo este otro factor que limita su crecimiento y desarrollo.

En la parroquia El Vecino, los avances en cuanto a cultura tributaria se reflejan en una mayor conciencia sobre la importancia de contribuir

2 Tales como: planificación y elaboración de presupuestos, programas informáticos contables, manejo de cuentas dentro del sistema financiero, estados financieros, entre otros.

3 Microempresa: 1-9 trabajadores, ventas anuales iguales o menores de cien mil dólares; Pequeña empresa: 10-49 trabajadores, ventas anuales entre cien mil uno y un millón de dólares y Mediana empresa: 50-199 trabajadores, ventas anuales entre un millón uno y cinco millones de dólares de los Estados Unidos de América (Código Orgánico de la Producción, Comercio e Inversiones y sus Reglamentos). 
tributariamente al desarrollo del país, aunque prevalece el temor a evitar sanciones. Resultados similares se encuentran en la investigación realizada por (Minchala \& Peña, 2013) referente al perfil socioeconómico del contribuyente cuencano.

Existe una buena percepción acerca de la calidad de los servicios ofertados por el SRI. En su informe de labores del año 2014, dio a conocer que ha prestado atención a los contribuyentes entre: atención personalizada a través de ventanillas en las diferentes agencias de todo el país, asistencia vía telefónica, a través del portal web y de los servicios virtuales (SRI, 2014).

\section{Conclusiones}

El estudio de la caracterización tributaria empresarial en la parroquia El Vecino del cantón Cuenca, revela la naturaleza marcadamente privada de tipo personal y familiar de la actividad empresarial, muy pocas empresas han logrado trascender en el mercado más de 20 años funcionado. El 90\% de los contribuyentes del cantón Cuenca se encuentran bajo la categoría de personas naturales no obligadas a llevar contabilidad y RISE (Minchala \& Peña, 2013) .

En el ámbito laboral, destacan relaciones patronales y contrataciones de carácter informal, atentatorios a los derechos de los trabajadores. La falta de preparación profesional propicia el sur- gimiento de actividades de subsistencia y autoempleo de bajo nivel, propietarios sin capacitación que desarrollan actividades de gerencia, contables y tributarias; y, reducido uso de tecnologías de la información y comunicación.

Económicamente la mayor parte de empresas ubicadas en la parroquia "El Vecino", resultan ser débiles, con montos de ventas mensuales que no superan los USD $\$ 500,00$ frente a compras que duplican este valor; $y$, costos y gastos de operación que casi igualan a las ventas. La naturaleza de subsistencia y microempresarial es evidente en la alta rotación de inventarios, con flujos que experimenta movimientos diarios o semanales. Así también el movimiento financiero es de corto plazo, poco vinculado con la banca tradicional (Tobar, 2014).

La percepción que las empresas tienen sobre la calidad de atención del SRI es satisfactoria, pocas empresas han formalizado sus quejas o reclamos; la mayoría manifiesta haber recibido atención a sus solicitudes y haber sido atendidos de manera respetuosa, eficiente y oportuna. Esta situación refleja el esfuerzo institucional del administrador como funcionario público, comprometido no solo con el conocimiento técnico fiscal y tributario, sino también como una persona capaz de aconsejar profesionalmente y alinearse con los objetivos del país (Carrasco Vicuña et al., 2012). 


\section{Bibliografía}

Asencio, K. (2014). Análisis tributario de los grandes contribuyentes del sector automotriz del Ecuador periodo 2007-2012 (tesis de maestría). Recuperado el 15 de octubre 2015 de: http//repositorio. ug.edu.ec/bitstream/redug/6253/1/ AN\%C3\%81LISIS\%20TRIBUTARIO\% 20 DE $\% 20$ LOS $\% 20$ GRANDES\%20CONTRIBUYENTES\%20DEL\%20SECTOR.pdf

Carrasco Vicuña, C. M., Andino Alarcón, M., Arias Urvina, D., Carrillo Maldonado, P., Carpio Rivera, R., \& Chiliquinga Carvajal, D. (2012). Una nueva política fiscal para el Buen Vivir. La Equidad como soporte del pacto fiscal. Quito: Ediciones AbyaYala.

Código Tributario [Código]. (2014). [consultado 6 de junio 2016] Disponible en: http://www.abaco.ec/equal/ documentos/scribd.php?id=13944

Constitución de la República del Ecuador [Const.] (2008). Artículo 283. [consultado 5 julio 2015] Disponible en http://www.asambleanacional.gob.ec/sites/default/files/ documents/old/constitucion_de_ bolsillo.pdf

Constitución de la República del Ecuador [Const.] (2008). Artículo 285. [consultado 5 julio 2015] Disponible en http://www.asambleanacional.gob.ec/sites/default/files/ documents/old/constitucion_de_ bolsillo.pdf

Hopenhayn, M. (2008). Cohesión Social: entre inclusión social y sentido de pertenencia. En J. Granda (Ed.), Pobreza, exclusión y desigualdad 1⿳a. Edición (pp. 189-204), Quito: FLACSO.
Instituto Nacional de Estadísiticas y Censos (2010). Información censal poblacion $y$ vivienda 2010. [consultado 26 noviembre 2015], Disponible en: http:/www.ecuadorencifras.gob.ec/ informacion-censal-cantonal/

Lora, E. (2008). El futuro de los pactos fiscales en América Latina. Recuperado el 25 de noviembre 2015 de: https://publications.iadb.org/ bitstream/handle/11319/2173/ E1\%20futuro\%20de\%20los\%20 pactos $\% 20$ fiscales $\% 20$ en $\% 20$ Am\%C3\%A9rica\%20Latina.pdf;j sessionid $=6$ DC55A72F78E4125E9 05D18C1C9F656E? sequence $=1$

Minchala Ávila, T. C., Peña León, V. L. (2013). Perfil socioeconómico del contribuyente cuencano sujeto al control del Servicio de Rentas Internas en sus obligaciones tributarias en el periodo 2010-2011 (Tesis de pregrado). Recuperado de http://dspace.ups. edu.ec/123456789/4264

Montesdeoca Campoverde, M.I., \& Espinoza Cabrera. J.M. (2015). Impacto del Régimen Impositivo Simplificado en las microempresas de la ciudad de Cuenca y análisis de los resultados obtenidos en las recaudaciones de los años 2012 y 2013 (Tesis de pregrado). Universidad de Cuenca, Facultad de Ciencias Económicas y Administrativas, Carrera de Contabilidad y Auditoría, Cuenca.

Orduna Díez, L. (2003). La empresa y el problema desde su gobierno: Análisis desde la ética. Cuadernos de Estudios Empresariales, 13, 215-287.

Quituisaca Chillogalli, S. G., Sinchi Morocho, M. J. (2012). Análisis del impacto económico que genera el RISE en el sector popular Tiendas de Barrio del área urbana en la ciudad 
de Cuenca en el periodo 2007-2011 (Tesis de pregrado). Recuperado de http://dspace.ups.edu.ec/handle/123456789/2957

Sen, Amartya, (1999). La libertad individual como compromiso social. Quito: Ediciones Abya-Yala.

Servicio de Rentas Internas (2014). Informe de labores Servicio de Rentas Internas enero - diciembre 2014. Recuperado el 15 de octubre 2015 de: www.sri.gob.ec/.../INFORME+ ANUAL+DE+LABORES+2014. + EXT-+docx.pdf

Tobar, L. (2013). Competitividad de las microempresas en Cuenca Ecuador. Revista Internacional Administración Eु Finanzas, 6 (7), 122-129. (2014). Las pequeñas y medianas empresas en Cuenca, su impacto en la economía local (tesis doctoral), Recuperado de https://www.google. com.ec/url?sa $=\mathrm{t} \& \mathrm{rct}=\mathrm{j} \& \mathrm{q}=\&$ \&esrc $=$ $\mathrm{s} \&$ source $=$ web\& $\mathrm{cd}=1 \&$ ved $=0 \mathrm{ah}$
UKEwjWl-W-qrfNAhVEdh4KH UQBBogQFggaMAA\&url=https $\% 3 \mathrm{~A} \% 2 \mathrm{~F} \% 2 \mathrm{Fbuleria}$.unileon.es\% 2Fbitstream\%2Fhandle\%2F10612 $\% 2$ F3678\%2Ftesis_ee6a9e.PDF\% 3Fsequence $\% 3 \mathrm{D} 1$ \&usg=AFQjCN GmlGCBoNPqNkWlvmUXvSFp SFyx9w\&sig2=Z05ZY_nlarv_xK_ Mhvle7g\&bvm=bv.124817099,d. $\mathrm{dmo} \& \mathrm{cad}=\mathrm{rja}$.

(2015). Análisis competitivo de las pequeñas y medianas empresas en Cuenca Ecuador. Revista Internacional Administración $\mathcal{E}$ Finanzas, 8 (3), 79-92.

USAID (2005). Microempresas y micro finanzas en el Ecuador: Resultados del estudio de línea base de 2004. Recuperado el 30 de junio 2016 de: http://www.uasb.edu.ec/ UserFiles/381/File/MICROEMPRESAS\%20Y\%20MICROFINANZAS\%20EN\%20EL\%20 ECUADOR.pdf.

Recepción: 29- 03-2016- Aceptación: 22-06-2016 